\title{
EDITORIAL
}

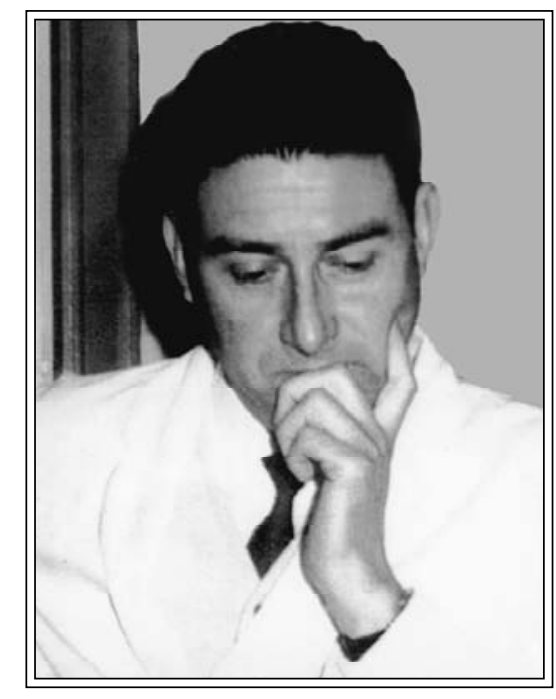

\section{Dr. Oscar Peña Núñez}

Nacido en Ovalle el 23 de Junio de 1929, realizó sus estudios primarios y secundarios en el Liceo de esa ciudad. Ingresó a la Facultad de Medicina de la Universidad de Chile en el año 1950, realizando su internado en el Hospital José Joaquín Aguirre. En su período de estudiante sufrió un accidente de tránsito con fractura completa de su pierna derecha, lo que motivó varias intervenciones quirúrgicas y un retraso en sus estudios por más de un año, quedando con una ligera secuela para caminar.

Recibió su título de Médico Cirujano en el año 1958 e inmediatamente una Beca de perfeccionamiento en el Hospital del Salvador con el Dr. Ignacio González G. Permaneció en ese hospital hasta fines de 1959, fecha en que se traslada a Valdivia, interesado en participar en la reciente creada Facultad de Medicina, iniciando sus actividades académicas como Profesor de Anatomía en la Escuela de Enfermería, actividad que desempeñó hasta la creación de la Escuela de Medicina. Posteriormente participó de forma activa en la creación de la carrera clínica de la Escuela. A la par con sus labores universitarias, participó como cirujano en el Hospital Regional, preferentemente en el cargo de Urgencia, siendo su Jefe hasta su alejamiento de la ciudad.

A pocos meses de su llegada a Valdivia, el 22 de mayo de 1960, estando en turno en el antiguo Hospital Regional, lo sorprende el terremoto. Su férrea y tranquila actitud frente a este desastre, le permitió una adecuada y brillante evacuación del Hospital, totalmente inutilizado. Logró establecer una Posta de Primeros Auxilios en el terremoteado recinto de Urgencia del primer piso y junto a un reducido personal auxiliar enfrentó la situación sanitaria de la ciudad en las primeras 24 horas, las más difíciles de esta catástrofe. Posteriormente le fue encomendada la misión del traslado del Hospital al edificio de la Escuela Normal, único edificio viable para un hospital de emergencia. Este recinto sirvió como Hospital Público hasta el $1^{\circ}$ de agosto de 1963, fecha en que abrió sus puertas el nuevo Hospital Abraham Lincoln, donado por EE.UU. y que posteriormente se denominó J.F. Kennedy, en honor al presidente estadounidense asesinado. 
El 10 de Septiembre de 1960 contrae matrimonio en Valdivia con María Isabel Bizama, oriunda de Valdivia, a la cual conoció poco tiempo después de llegada a la ciudad. De su matrimonio nacen 5 Hijos: María Alicia, profesora de inglés y psicóloga, actualmente en Inglaterra; Oscar, arquitecto en la Universidad de Chile; Miguel, veterinario en la Universidad de Reading, Inglaterra; Paulina, periodista en la Universidad de Birmingham, Inglaterra; Lía Gabriela, diseñadora gráfica en el Instituto Profesional del Pacífico en Santiago.

En 1964 el Dr. Peña logra una beca de la Doherty Foundation en la Lahey Clinic en Boston, junto al eminente cirujano Dr. Warren. Permaneció en Boston hasta 1966, lo que le significó una extraordinaria experiencia en patología biliar, preferentemente reparaciones de vía biliar con derivaciones biliodigestivas con asas desfuncionalizadas, como también la cirugía gástrica.

Conocí a Oscar 1 año antes que partiera a Boston y, al cabo de poco tiempo de conocernos, se estableció un estrecho vínculo, tanto personal como profesional, situación que perduró mucho más allá de su alejamiento de Valdivia. Establecimos un estrecho contacto por carta durante este tiempo, en que me contaba de sus participaciones en operaciones biliares y, por sobretodo, la necesidad de la cirugía experimental en todo programa de formación de Becados en Cirugía. A su regreso, comenzamos en el pabellón de Veterinaria, gentilmente facilitado por el Dr. Schüler, Decano de la Facultad de Medicina de la Universidad Austral de Chile, la tan necesaria cirugía experimental en perros. Realizamos en conjunto cerca de 20 gastrectomías totales con interposición de asa yeyunal desfuncionalizada y con anastomosis esófago duodenal, con excelentes resultados, lo que nos permitió realizar esta misma operación en pacientes con cáncer gástrico. Además hicimos varias derivaciones biliodigestivas en perros, practicando la técnica del Dr. Warren. Este período fue excepcional y muy enriquecedor en mi formación de cirujano.

El Dr. Peña destacó por su carácter benevolente y por su permanente interés de perfeccionamiento y renovación. Consiguió un enorme prestigio dentro de la comunidad, logrando el respeto y admiración de todo el equipo de cirujanos, personal auxiliar y administrativo, como también de todos sus pacientes.

Dominaba una técnica quirúrgica depurada, reglada y elegante, rápido en las urgencias y con gran criterio frente a operaciones electivas. Por sus condiciones profesionales fue llamado por el American College como Fellow a participar en esta Institución. También participó activamente en la Sociedad de Cirujanos de Chile y en la Sociedad Médica de Valdivia, sociedades en que fue miembro activo.

Es muy lamentable que una figura como Oscar Peña haya logrado sólo una corta trayectoria profesional.

Por circunstancias personales y por sus dolencias articulares permanentes en el último tiempo, decidió trasladarse a Santiago y fue en Mayo de 1973 cuando inició sus labores en el Hospital de la FACH. Sólo un mes después se le descubre una leucemia, enfermedad que rápidamente lo llevó a la muerte, falleciendo el 18 de Septiembre de 1973.

Su sepultación se llevó a cabo en el Cementerio Católico de Santiago.

En su honor se le dedicó la primera sala de docencia y biblioteca de la Facultad de Medicina en el Hospital Kennedy, hoy desaparecido dicho establecimiento, y una sala de la Prodecanatura lleva su nombre como reconocimiento a su brillante labor docente-asistencial.

\author{
Dr. Eberhard Schultz $H$. \\ Profesor Titular de Cirugía \\ Facultad de Medicina \\ Universidad Austral de Chile
}

